\title{
Building Community Through Virtual Learning Communities
}

\author{
Deborah Gill, (Email: djg25@psu.edu), Pennsylvania State University, DuBois
}

\begin{abstract}
The present study describes and discusses the use of a virtual community to build language and culture skills. According to the National Standards Project (2004), "The United States must educate students who are linguistically and culturally equipped to communicate successfully in a pluralistic American society and abroad." Through the use of World of Diversity, students not only have an opportunity to practice their language skills, but also meet all other national standards (i.e., communication, cultures, comparisons, and communications) in a unique and fun way.
\end{abstract}

Introduction

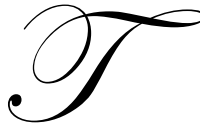

he use of computer technology in foreign language classes has been gaining popularity for the past several years. These technologies range from such basic components as language

learning CD ROMs to the use of the Internet for informational searches and/or the use of electronic workbooks to provide the drill-and-kill necessary to be able to survive in the contentbased/task-based communicative language classroom. From these static (or semi-static) mediums has grown synchronous communication, such as email exchanges, threaded discussion boards, blogs, etc. The present study will focus on yet another synchronous communicative tool, virtual communities.

\section{Purpose and Description of the Project}

This project grew out of a number of important factors, including the lack of Hispanic language in the community and surrounding communities, the non-existence of Hispanic television and radio station broadcasts available to the community, and, most importantly, the need for more authentic language and cultural materials and input. According to the National Standards Project (2004), "The United States must educate students who are linguistically and culturally equipped to communicate successfully in a pluralistic American society and abroad." Therefore, students should be provided with as many authentic materials as possible; a virtual community is a tool for providing this information. World of Diversity provides such a venue.

World of Diversity (http://diversity.ds.psu.edu:7000 and shown as Figure 1 below) is a web-based virtual community using enCore Xpress, an online virtual learning environment. World of Diversity was developed in 2001 as a virtual community created to promote diversity, collaboration, and interdisciplinary studies. Unlike text-based synchronous virtual communities, World of Diversity incorporates not only text, but rather images, sound, and video. World of Diversity is currently divided into a number of different sectors with the focal point at "World of Diversity", the home of all new characters as well as any guest log-ins. When one connects, they are greeted with a Welcome Message and "It's a Small World" playing in the background, promoting the idea of everyone working together and collaborating with one another. Currently there are six main sectors: (1) World of Friends, (2) 
Programmer's Alley, (3) Women's Studies, (4) Kid's Zone, (5) World of Languages, and (6) World Cultures. For the present paper we will be concerned only with World of Diversity for the acquisition of language and culture, and therefore the sectors entitled "World of Languages" and "World Cultures".

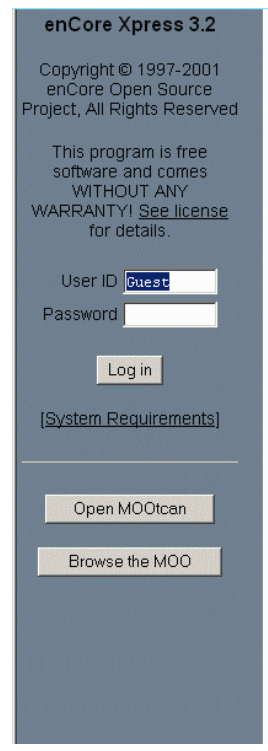

\section{Welcome to World of Diversity!}
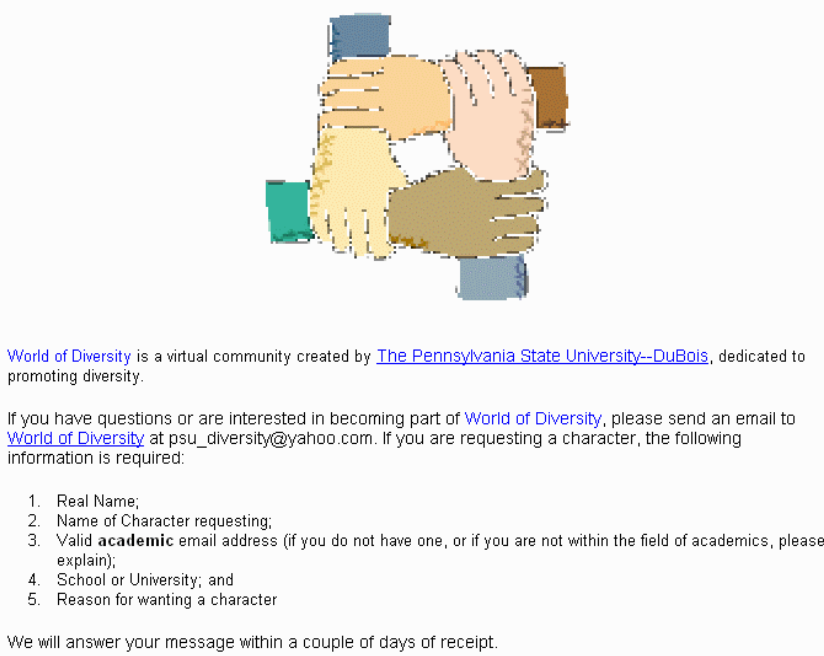

Figure 1: World of Diversity

With regard to foreign and second language studies, World provides second language learners and native speakers of their respective languages a forum in which to communicate. This communication may be in the form of text-based messages during real time meetings, collaborating on projects in real time or through projects which are set up through a virtual project board (VASE in World-see Figure 2 below), creating rooms, and objects using text, images, videos, and/or sound.

The Virtual Project Board is located within World and provides a platform in which those with permissions to create (i.e., anyone who has become a "builder" or who is a "programmer") may design a project for anyone who is part of World to work on. The designer has the ability to accept or reject a request to work on a project. Figure 2 below shows the basic layout of a project. The designer provides a Project Title, and can designate a course (or courses) or leave the project open for anyone to participate. The participants then "register" to work on the project and state what it is that they want to do. As they are working, the can submit what they are doing to be reviewed and/or to receive comments and guidance from the Designer. The Designer may delete participants and/or content he/she feels is not appropriate for the project. 


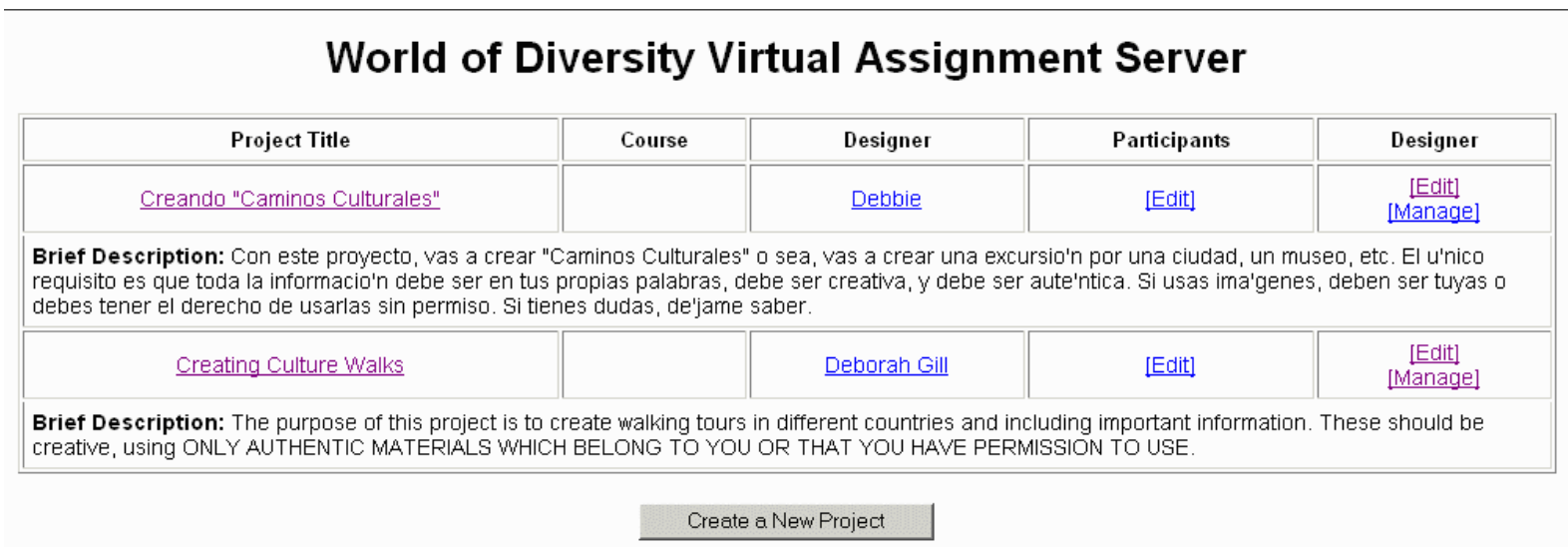

Figure 2: Virtual Project Board

Figure 2 is a description of "Culture Walks" which are being created in Spanish, with a parallel project in English. "Culture Walks" (Gill 2005) are virtual walking tours which provide an opportunity to travel to foreign countries. These tours are comprised of written narrations, video and audio clips, and/or authentic photos taken by the author of this paper or photos which have been donated for use free of copyright issues. The "Brief Description" within each Project explains the purpose as well as any special requirements (i.e., in this case, the use of authentic materials).

\section{Discussion}

Two areas have been set up for foreign and second language learners. These include World of Language and World Cultures. The separation of World Language and World Cultures would appear to contradict the idea which we have proposed here of building community. However, this is not the case; both areas support and promote the building of community. The difference in the two sections is the language in which it is presented. World of Language includes cultural information, activities, and communities which have been built in the native language. For example, Mexico is under construction there. All of the information is written in Spanish, being the native language of that country. In the area in which England is being developed, everything is in English.

On the other hand, World Cultures has similar areas under construction, but everything in that area is written in English. The purpose and the idea here is that those who may not know a foreign language but would like to become part of another culture (another community); can immerse themselves in that culture in this area but within their own language.

\section{Implications for Instruction}

One of the primary goals in second and foreign language instruction is to promote language development and cultural competency, while reaching state and national standards. The use of World and the building of community, both with other second language learners as well as with native speakers of a foreign language, aid in reaching these goals. Therefore, building community through the use of a virtual community has positive implications on instruction.

The pedagogical motivation for the use of World is to improve student skills in the areas of reading, writing, listening, speaking and cultural competence. It is also an appropriate tool for addressing all state and national standards. 


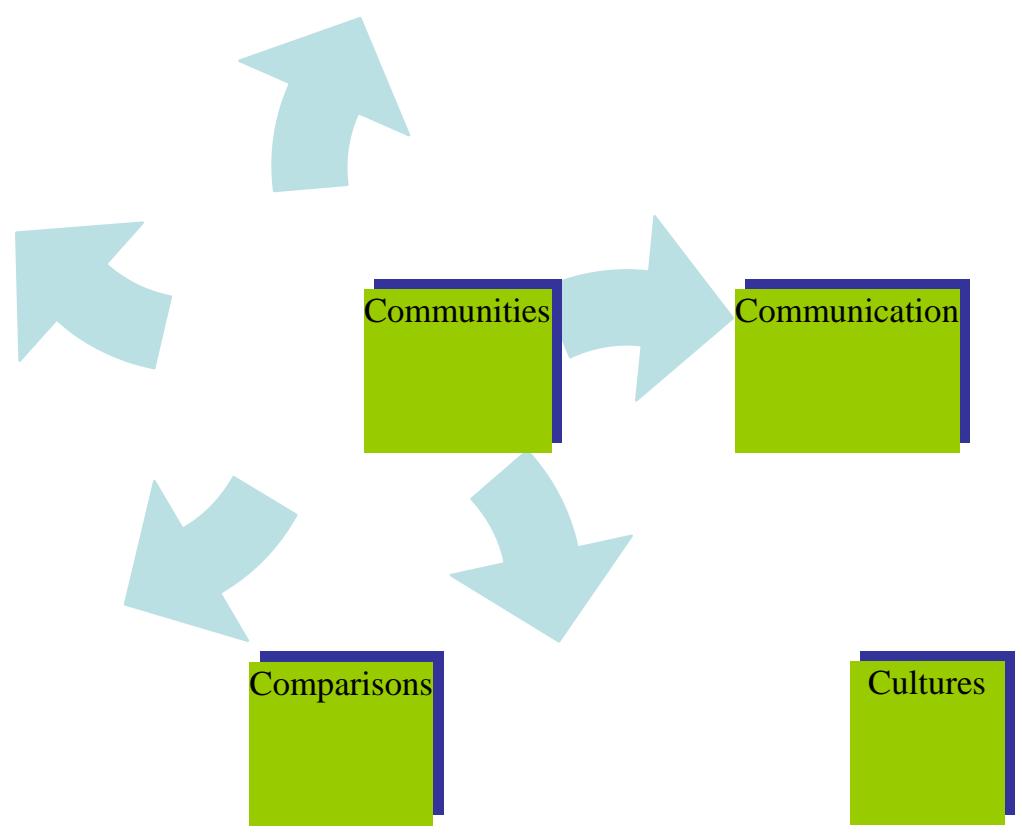

Figure 3: Representation of National Foreign

\section{Language Standards}

Figure 3 above represents the National Connections

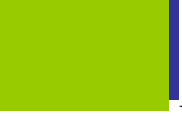

Foreign Language Standards which are also incorporated into each and every state standards and benchmarks for foreign language development. As one can see, each standard is connected to the next to form a strong link between the five components. If we are to "educate students who are linguistically and culturally equipped", we must provide an opportunity for students to develop each of these areas. This is accomplished by:

- providing visually stimulating material;

- addressing a wide variety of learning styles;

- incorporating authentic materials into the classroom;

- promoting on-line communication in the target language;

- encouraging cultural comparisons; and

- providing students the opportunity to achieve success in all skill areas (reading, writing, speaking, listening, and cultural competence)

The activities which will be discussed briefly below will demonstrate how each of these areas (communities, cultures, etc.) are met through building community.

\section{Implementation in the Classroom}

\section{Language Acquisition and Cultural Competence Activities}

Biggs and Telfer (1987) suggest that learning is fostered under certain circumstances. These include the motivational context, interaction with both peers and teachers, a well-structured knowledge base, and a high degree of learning activity. A virtual community which may include text, audio, and 
video, as well as synchronous and asynchronous communication, provides these opportunities for acquiring language and culture and building community.

\section{Motivational context and interaction}

At the beginning and end of each semester, students are given a Language Attitude Questionnaire in which questions related to the use of technology (including virtual communities) are part. The purpose of this questionnaire is to first observe the attitude towards belonging to a community in which the students are not a part and at the end of the semester to gauge whether or not this attitude has changed in any way. Below are seven questions which we analyzed:

1. I enjoy lessons on the computer.

$\begin{array}{lllllll}\text { strongly disagree } & 1 & 2 & 3 & 4 & 5 & \text { strongly agree }\end{array}$

2. I have used virtual communities, chats, IRC, etc. in classes before and enjoyed it. $\begin{array}{lllllll}\text { strongly disagree } & 1 & 2 & 3 & 4 & 5 & \text { strongly agree }\end{array}$

3. Working and collaborating with others is interesting. $\begin{array}{llllllll}\text { strongly disagree } & 1 & 2 & 3 & 4 & 5 & \text { strongly agree }\end{array}$

4. It would be/is beneficial to talk with other language learners and native speakers of Spanish. $\begin{array}{lllllll}\text { strongly disagree } & 1 & 2 & 3 & 4 & 5 & \text { strongly agree }\end{array}$

5. I prefer using a textbook than talking in class. $\begin{array}{lllllll}\text { strongly disagree } & 1 & 2 & 3 & 4 & 5 & \text { strongly agree }\end{array}$

6. I prefer using a textbook and working alone than collaborating with other people. $\begin{array}{lllllll}\text { strongly disagree } & 1 & 2 & 3 & 4 & 5 & \text { strongly agree }\end{array}$

7. I think it is difficult to work with others collaboratively on line. strongly disagree 2 $3 \quad 4$ 45 strongly agree

A summary of the results of these questions can be seen in Table 1 below: 


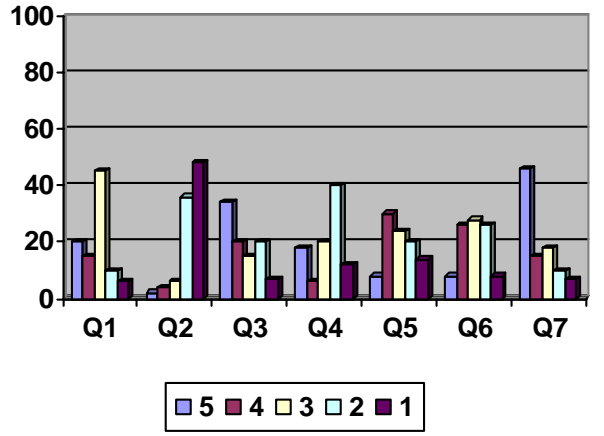

Pre-Language Attitude Questionnaire

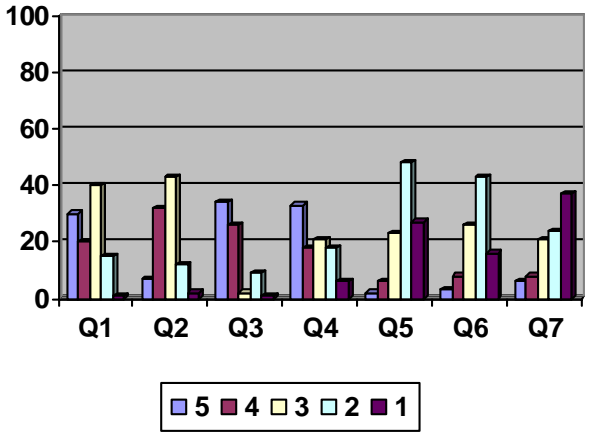

Post Language Attitude Questionnaire

Ninety-six students responded to both the Pre- and Post-Language Attitude Questionnaires. The results support the idea that, when given the opportunity to build community, most students will choose collaborative activities over those in which they are working alone and passively learning.

It is well-known that, in order for a student to learn a language and to become culturally competent, the student must be motivated and have a purpose for wanting to learn a language and about different cultures. Gardner and Lambert (1959) distinguished between two types of motivation: integrative and instrumental. Integrative motivation deals with a learner's positive attitude toward the target language group and its culture, including meeting and interacting with other members of the community. On the other hand, instrumental motivation deals with learning a language for a purpose, such as getting a job, passing an exam, etc.

Looking at the Language Attitude Questionnaire results shown in Table 1 above, looking specifically at Questions 5 and 6 of the Pre-Language Attitude Questionnaire, students noted that they preferred passive learning, i.e., using and reading their textbooks and working alone, to working collaboratively with others. However, after working within a virtual community environment, the results showed that students overwhelmingly preferred to collaborate with others than work alone. Their written comments also demonstrated this point:

- “All Spanish classes should be organized this way! In other classes I've taken, you just memorize and then forget because you aren't using it anymore. This way I have to remember so that I can keep using it!”

- "My partner was awesome! Even if I didn't know a word or how to say something, or if I wrote something that wasn't quite right, he didn't get mad, he just helped me. I've learned to some any cool expressions with him!”

- "This was really a challenge, but it was really fun too. I think I learned more Spanish this way even though I wasn't always just reading. And my tests were good too!”

- "I learned a lot. I wish I could have done this in my other classes."

The majority of comments were similar to the ones above, although there were a few students who did not see the experience as positively:

- "I wish we worked more on grammar and had more practice with the verbs. I don't think working with other students helps at all."

- "Working with a native speaker was too stressful. If I wanted to talk with native speakers I would either go to another country to do it or I would go to a chat room. What a waste of time." 
- "I was only taking this class because I had to. Why should I have to talk with people I don't know?”

The students who were positively affected by the virtual community activities possessed integrative motivation and viewed the experience very positively. The more they worked with their collaborative partners and the more they interacted in the environment, they became part of the community. Test results were not affected negatively with the more student-centered classroom interactions. To the contrary, test results have shown an increase in all five skills. On the other hand, students who were less responsive appear to possess more instrumental motivation for taking Spanish, i.e., passing the class because it was a requirement, wanting more book work, tending to mean more teacher-centered learning.

In the following sections, we will discuss the types of activities which help to build community while providing students with an environment to build their language skills.

\section{Language acquisition activities}

Whether or not students are motivated, we are challenged with developing activities which will provide the student the possibility to use the language in as authentic a context as possible. Instead of the teacher-centered classroom, World provides the perfect opportunity for students to build community through collaborations with other second language learners as well as with native speakers of another language (in this case, Spanish).

A variety of language acquisition activities can be (and have been) created in World. These activities are set up to meet the National Standards throughout the country, with the "speaking" component being a follow-up, oral in-class activity to what students are working on in World. The types of activities, of course, will depend upon the students' level of proficiency and the purpose of the activity. Sample Structured Knowledge and Learning Activities, as well as Language Acquisition Activities can be found as Appendix 1 and 2, respectively, of this paper.

In addition to activities which have been specifically created for students learning a second language, much of the learning that goes on is incidental. As Fanderclai (1995:8) states, "...Quite possibly they learn more from projects and activities they invent for themselves than from any I assign; certainly they learn things I could not teach them in our four-walled classroom." Students learning a second language have experimented and created their own objects in the target language many times and come to share the robot, or the "talking baseball", or whatever they want without having been assigned to do it. This play has led to increased language (both grammar and vocabulary) and culture ability.

Jaeger (1995:68) discusses the constraints of on-line education:

In on-campus classes, instructors tend to default to a control mode of teaching; that is, when students fail to manipulate materials as planned, a hovering instructor provides coaching or even micro-modeling of behaviors. In distance science education contexts, these behaviors are impossible. Participants are forced to be independent, to follow directions carefully, and to try alternatives when the first efforts fail. As a result, participants are self-directed, taking ownership of ideas and goals presented in the course. They also learn to depend on one another.

Applying Jaeger's ideas not to an on-line class, but rather to the technology-infused second language course (and more specifically to a virtual community), we see by the comments of students that 
they were able to distinguish between simple memorization for succeeding on an exam and learning (i.e., taking ownership and building community). Table 2 below presents some student comments related to their perceptions on the development of language skills and true learning:

\section{Table 2: Student Comments and Perceptions}

"Before, I would just memorize the words at the end of each chapter and getting good grades on the exams. Now I have to use it [the language]."

$>$ "I was hesitant to use my Spanish when I first started. Now I try to use it and I don't worry so much."

$>$ "I've learned so much more Spanish this semester! I'm not as afraid to talk now and want to improve that too."

$>$ "I find myself thinking in Spanish when I'm driving, thinking about the projects that I'm working on with my partner."

An example of a representative activity done is a discussion of what "to give someone the evil eye" means, signifies, represents. Students had been reading a novel in which this particular theme came up. Using World as a meeting place for students and anyone else who might have been connected at the time, the instructor broached the subject of "the evil eye", which provoked a very lively discussion between students with many different beliefs. An analysis of the discussion logs also showed equality within discussions; that is, students who would not generally speak in front of the class or participate very actively in class discussion ventured to participate in the on-line, collaborative discussions. It has been stated that this equality is due to (1) a reduction in social context clues which are related to race, handicap, gender, accent and status (Sproull and Kiesler 1991); (2) a reduction of nonverbal cues (smiling, frowning, hesitating, etc.) (Finholt, Kiesler \& Sproull 1986); and (3) the ability of participants to contribute at a pace which is suitable to him/her (Sproull and Kiesler 1991). Student reactions to these collaborative activities was quite positive. Comments such as "I wasn't nervous at all about making mistakes," "I didn’t know I knew so much Spanish!", and "We should do this more often” are all representative responses.

\section{Cultural competence activities}

In addition to language acquisition, another important component in building community and becoming part of that community is the cultural aspect. Second and foreign language learners are always taught that language and culture go together. Therefore, it is not enough just to memorize a list of words. Instead, it is necessary to learn about the culture and be able to compare and contrast that culture with one's own as well as with other cultures. We will discuss one way to build cultural competence in order to belong to a community here: the use of Collaborative Projects. In addition, Appendix 3 to this paper gives sample Cultural Competence activities in which one can take part while in World of Diversity.

\section{Collaborative Projects}

World offers many opportunities to participate in collaborative activities. These activities may be formal or informal collaborations, depending upon the purpose of the assignments.

\section{Informal Collaborations}


Informal collaborations are projects which may benefit the entire community in World or only a small, select group and may be built by one person or by a group of people. These collaborations might include an object that can be used by all members of World of Diversity, such as a robot, a restaurant, a game, etc. They may be interactive, i.e., where one talks with the robot and the robot responds, or they may be static, i.e., a book of recipes, of poems, etc. Once the project is completed the individual or the group who has created it will announce its availability to the community, including its location, purpose, etc.

A second type of informal collaboration might be an object which is created for a specific group of individuals. For example, a member of the World of Diversity community creates a stereo system (text-based, without or without photos, and with a midi clip if not copyrighted or with permission to use) which is placed in a private "residence" on World. That stereo is part of that member's objects and he/she may work with friends to come up with a stereo system that they all like and will use. This is not for the entire community; it is for a select community of individuals.

Finally, a third type of informal collaboration is one in which a group from the World of Diversity community requests to build a region and come up with a plan on how to do that, what it will include, and who will be allowed to join in the creation of that area. This might be between students and/or teachers who have similar interests and therefore talk with one another and decide to work on a project together. These projects are natural and encouraged!

\section{Formal Collaborations}

Formal collaborations are collaborations which are set up, either by the administrator or by one or more teachers or students. They entail specific tasks and generally include a specific beginning and/or ending date.

This type of collaboration is easy to set up in World. We would suggest that teachers get to know each other first, through (1) meeting each other in World of Diversity, (2) subscribing to the teachers news group found within World, (3) exploring ongoing projects through a review of the VASE database and (4) exploring areas and/or projects already in progress.

\section{Assessment}

One of the difficulties of collaboration and with the use of virtual communities to build community is that of classroom assessment. Since the focus of this paper is not this topic, we will just briefly mention it here.

The use of a virtual community for building community cannot be assessed in the traditional test taking mode, as the learning and the learning process is not the same. So, how should we assess students within this type of environment? It has been suggested that, instead of looking at accuracy, that the assessment should come from doing and completing the task; in other words, this replaces the "test". Therefore, students who are (1) speaking in the target language, (2) collaborating in the target language, and (3) becoming part of the community is what should be evaluated and not whether or not they can explain a grammar point, i.e., why they used a preterite tense verb instead of an imperfect tense. As Hall (1998) states, "This may seem very simplistic, but when compared to testing a learner's ability to fill in the blanks or choose the correct answer from four choices, it cannot be denied that having an authentic conversation with native Spanish speakers is a far better test of a learner's ability in the target language.” A student who is able to become part of a community has shown that he/she has passed the test. 


\section{Student Reaction}

We have already noted student reactions to a number of different activities and to the idea of building community as a whole Working with the context of a virtual community has offered students opportunities that are foreign to them but also which provide them a new medium for learning.

It provides an opportunity for students to be creative and have a voice, while at the same time learning about new cultures.

In order to see if students continue to be part of the community after they have finished a course as well as when they have graduated, we have continuously monitored character log in and we have sent out a number of different surveys. For the past two years, approximately $62 \%$ of the students who used World for courses have continued to log on. Some are active learners in the foreign language, creating objects for other students ("because I learned better that way") and talking with native speakers. Others, while fairly inactive in the foreign language part of World, have become part of the larger community, creating public areas for others to enjoy. Therefore, the feeling of being part of a community appears to be present.

Our surveys have had less of a success in responses. Only $43 \%$ of those sent out have been returned. Of those, $72 \%$ say that they are still active in World, either in the foreign language or in the larger community. As these are anonymous surveys, there is no way to know who has stayed active in what. Of the $28 \%$ who are no longer active, the response to the question: "If not, why not?" (referring to why they are no longer part of the community), 83\% responded that it was due to "Outside obligations/No free time”, while the other $17 \%$ were split between not having access to a computer and "other".

Since World has more than doubled in size since its inception in October 2001, the concept of community seems to be appealing to some. Many of those who have joined have joined on the recommendation of others who have been a part. Hopefully we will have continued growth in upcoming years.

\section{Conclusions}

World of Diversity provides an environment for foreign language growth in all areas. First, students have the opportunity to be creative and to use their language skills through the creation of rooms and objects of their own. Second, students have the opportunity to use their language skills to collaborate with other second language learners and native speakers of the target language. This collaboration provides an opportunity for students to learn circumlocution techniques when they cannot express their thoughts. Third, the use of World builds community through collaborative projects and activities as well as through the building of virtual communities with language and/or cultural components. And fourth, community is also built through the cultural activities which are found both in the target language and in English. Through cultural activities, students become more immersed in the culture, make friendships, and learn about other cultures and peoples.

Finally, building community through virtual communities changes the dynamics in the classroom. First, no longer is the teacher the focal point, but rather the teacher is seen as a facilitator, with the power being given to the students. Second, negotiations for meaning must take place in order for everyone to be part of the community. Next, there is a natural move towards collaborative learning and peer interaction 
that does not take place in the classroom. Finally, students have access to authentic materials and are learning in an immersion context, automatically leading to the building of communities.

\section{References}

Biggs, J.B. and Telfer, R. (1987). The Process of Learning. Sydney:Prentice-Hall.

Fanderclai, Tari Lin. (1995). MUDs in Education: New Environments, New Pedagogies. Computer Mediated Communication Magazine 2/1:8.

Finholt, T., Kiesler, S. \& Sproull, L. (1986). An Electronic Classroom. Working paper. Carnegie Mellon University:Pittsburgh, PA.

Gardner, R.C. and Lambert, W.E. (1959). Motivational variables in second language acquisition. Canadian Journal of Psychology. 13:266-272.

Gill, Deborah. (2005). Hispanic Culture Through Culture Walks. Proceedings of the 2005 College Teaching \& Learning Conference.

Hall, Cathy. (1998). “Constructing” Language at MundoHispano. Unpublished paper. George Mason University, Fairfax, VA.

Jaeger, M. (1995). Science teacher education at a distance. The American Journal of Distance Education. 8.2:30-42.

National Standards for Foreign Language Education. ( 2004). $<<$ http://www.actfl.org/public/articles/details.cfm?id=33>>

Sproull, L. \& Kiesler, S. (1991). Connections: News ways of working in the networked organization. Cambridge:MIT Press.

\section{Appendix 1 \\ Sample Structured knowledge and learning activities}

Below is a list of Structured Knowledge and Learning Activities which are developed, or may be developed, in World.

1. Virtual Language Laboratory. The Virtual Language Laboratory has been set up as an authentic language lab would be set up in real life. There are tables for students to sit at, an "audio" library in which students can select listening activities from very basic to more advanced topics, a "video" library in which students can select short, thematic video clips to watch. Comprehension sheets are available if students are working alone, while students who come as a group may select to "discuss" the activity that they have seen/heard. The room has a notation that all conversation may be recorded. 
2. Information searches. These activities are teacher created activities in which students are provided with a thematic assignment to find information within World. These activities may be as basic as going to a specific area, reading, and marking down agreement in articles/nouns (for beginning classes), to more advanced activities in which students are asked to go, read a description or two, and then create an object themselves which is representative of what they have learned. Sample activities can be found (and downloaded) on the World of Diversity website at http://diversity.ds.psu.edu/World_of_Diversity/index.html.

3. Reading activities. These activities are activities in which students read the beginning of a story and have to decide between which one of two "paths" they will take, based on what they have learned so far, as well as their personal opinion. At the end of this activity, students usually write a new ending.

\section{Appendix 2}

\section{Sample Language Acquisition Activities}

Below is a list of Language Acquisition Activities which are developed, or may be developed, in World. The list is not all inclusive and any other activities that one would like to create would be welcome!

1. "Be creative!". In these activities, students are either given a specific task to do (i.e., write a description of themselves, set character messages which are vivid, etc. or they are given a broader project that they will work on creatively. Currently there are a number of projects in progress, including (1) two elementary schools who are building a "virtual school" together, (2) two University Spanish courses who are collaborating to create a new "region" (with its own name), and a number of counties within that region, complete with streets, houses, stores, restaurants, etc., and (3) Culture Walks in both English and a foreign language.

2. Reading circle. In these activities, students meet to discuss a common book that they are reading. One person functions as the facilitator (usually a faculty member), who will start off the discussion with a question, but then does not participate in the conversation. If the group goes off on a tangent, then the strand changes gears. When there is little to no conversation, a second discussion question is posed, and the same cycle begins.

3. Tertulia. Tertulia is held once a week. Generally a social, community, or political issue is chosen (i.e., "Should students be required to wear uniforms in High School?") and a discussion/debate takes place. There generally is not any lag time in these types of conversation, and a lot of language is learned.

4. Programmed objects. There are a number of objects which have been programmed by teachers and/or native speakers of languages for language acquisition purposes. An example would be an object in which a Spanish saying is given. Students may use these for discussion in World, or they may use them as discussion in face-to-face encounters. 


\section{Appendix 3 \\ Sample Cultural Competence Activities}

Below is a list of Language Acquisition Activities which are developed, or may be developed, in World. The list is not all inclusive and any other activities that one would like to create would be welcome!

1. Like to cook? Recipes provide a wide breadth of cultural knowledge to the classroom. There are a number of "recipe books" throughout World that provide foods from all over the world. With these virtual recipe books, students can compare foods from different countries as well as try to prepare different foods. These recipe books can also be seen as "language acquisition activities", with new vocabulary as well as the ability to practice grammatical forms which they have learned in their courses.

2. Mazes. Currently there are a series of mazes created in Spanish. These mazes go from very basic Spanish (i.e., "The capital of Mexico is ?”) to advanced (i.e., "In what year was La Celestina written?”). As students progress from the first level to the last, they are gaining cultural knowledge.

3. Culture Walks. These are virtual walking tours which may have oral narration as well as video clips, photos, and text. These can be used for very basic Spanish courses (they are not narrated in advanced Spanish) to more advanced Spanish language and culture courses. The information learned here can be transferred into the face-to-face classroom meetings for discussion as a class, a writing activity, a group collaboration, etc.

4. Let's Party!. Currently there are a number of "Dance Clubs" set up. Each one is a little bit different. Those who are interested in a quieter atmosphere might enter into a Club which has tables, chairs, and a jukebox. Those who are daring might enter into one of the Clubs that has a bar, dance floor, objects which will dance with you, fortune tellers, etc. Generally there are a number of objects which students can interact with, for example, asking for and getting food, asking to have one's fortune read, etc. Each of these activities builds on the five skills necessary in language learning.

5. Cultural Center. A Cultural Center has been set up in order to provide a place where members of the community can meet to discuss and compare cultural differences. This is also the spot where members of the community may view presentations on different holidays, folklore, etc. from around the world. Once again, this task meets all areas of the national standards. 


\section{Notes}

